\title{
STUDI HYGIENE SANITASI PENGELOLAAN MAKANAN DAN MINUMAN DI RSUD BANYUMASKABUPATEN BANYUMAS TAHUN 2017
}

\author{
Astri Priyani ${ }^{*}$, Zaeni Budiono**) \\ Jurusan Kesehatan Lingkungan, Politeknik Kesehatan Kemenkes Semarang, \\ Jl.Raya Baturaden KM 12 Purwokerto, Indonesia
}

\begin{abstract}
Abstrak
Pengelolaan makanan di rumah sakit, sebagai bagian dari sistem pelayanan kesehatan di rumah sakit yang mendukung upaya penyembuhan dan pemulihan penyakit melalui penyelenggaraan makanan yang higienis dan sehat.Kualitas makanan harus terjamin terutama bagi pasien karena rentan terhadap berbagai penyakit termasuk penyakit-penyakit yang ditularkan melalui makanan.Tujuan penelitian ini adalah mengetahui skor sanitasi penerapan enam prinsip hygiene sanitasi pengelolaan makanan dan minuman di instalasi gizi RSUD Banyumas tahun 2017.Jenis penelitian yang digunakan adalah deskriptif.Pengumpulan data dengan data primer yang meliputi observasi, wawancara, dan pemeriksaan kualitas mikrobiologi makanan \& minuman dan pemeriksaan kualitas mikrobiologi pada alat makan \& alat masak yang dilakukan di Laboratorium Kesehatan Masyarakat, serta data sekunder Instalasi Gizi Rumah Sakit Umum Daerah Banyumas.Hasil penelitian menunjukan penilaian sanitasi pada proses pengadaan bahan makanan, penyimpanan makanan dan penyajian makanan memenuhi syarat karena diperoleh skor $100 \%$. Penyimpanan bahan makanan, pengolahan makanan dan pengangkutan makanan dan tidak memenuhi syarat karena diperoleh skor $<100 \%$. Hygiene Sanitasi Pengelolaan Makanan dan Minuman Di Rumah Sakit Umum Daerah Banyumas tidak memenuhi syarat, permasalahan hygiene sanitasi dapat diatasi dengan menambah ventilasi disertai kasa pada ruang pengolahan, menyediakan tempat sampah berpenutup, serta memeriksa kesehatan penjamah secara berkala minimal 6 bulan sekali.
\end{abstract}

Kata kunci:hygiene sanitasi; makanan dan minuman; kesehatan lingkungan

\begin{abstract}
Hygiene study of food and beverages sanitation management in rsud banyumas, district of banyumas 2017. Hospital foods management is considered as a part of the health care system in hospital. It supports disease recovery through healthy and hygienic practices. Quality of food should be guaranteed especially for patients because they are susceptible to any diseases including foodborne diseases. The research purposed to know the sanitation score of implementation of six principles of hygiene sanitation on food and beverages management at the nutrition installation of RSUD Banyumas 2017. This descriptive research collecting the primary data by implementing observation, interview, and inspection of microbiology quality on food \& beverage and inspection of microbiology quality on cutlery \& cookware done in Public Health Laboratory, and collecting secondary data from Nutrition Installation of Banyumas Hospital. This research shows the sanitation assessment on foodstuffs procurement process, food-storage and serving food quality fulfilled the requirement with score 100\%. Storage of foodstuff, food processing and transportation of food and does not fulfill the requirement for obtained score $<100 \%$. Hygiene Sanitation of Food and Beverage Management at Banyumas General Hospital does not fulfill the qualification, sanitation hygiene problems can be overcome by adding ventilation with gauze in the processing room, providing a garbage with lid, and checking the handlers' health regularly at least once every 6 months.
\end{abstract}

Keywords:hygiene sanitation; food and beverages; environmenthal health 


\section{Pendahuluan}

Makanan merupakan kebutuhan pokok manusia yang dibutuhkan setiap saat serta memerlukan pengelolaan yang baik dan benar agar bermanfaat bagi tubuh.Makanan dan minuman yang memenuhi syarat kesehatan, perlu diadakan pengawasan terhadap hygiene dan sanitasi makanan dan minuman. Utamanya adalah usaha yang diperuntukan untuk umum seperti rumah sakit, restoran, rumah makan, atau pedagang kaki lima mengingat bahwa makanan dan minuman merupakan media yang potensial dalam penyebaran penyakit (Depkes RI,2004). Pengawasan terhadap hygiene dan sanitasi makanan dan minuman bertujuan agar selalu mempertahankan kualitas makanan baik secara bakteriologis, kimiawi maupun fisik.

Kualitas makanan harus terjamin setiap saat, agar masyarakat sebagai pemakai produk makanan tersebut dapat terhindar dari penyakit atau gangguan kesehatan serta keracunan akibat makanan, terutama bagi pasien yang sedang dirawat di rumah sakit yang tubuhnya dalam kondisi lemah, sehingga sangat rentan terhadap berbagai penyakit termasuk penyakit-penyakit yang ditularkan melalui makanan. Pengelolaan makanan yang dilakukan di rumah sakit perlu mendapat perhatian yang seksama (Dirjen PPM dan PLP Depkes 1996, h : 4 )

Pengelolaan makanan di rumah sakit, sebagai bagian dari sistem pelayanan kesehatan di rumah sakit yang mendukung upaya penyembuhan dan pemulihan penyakit melalui penyelenggaraan makanan yang higienis dan sehat. Prinsip-prinsip dasar sanitasi penyelenggaraan makanan di rumah sakit pada dasarnya tidak berbeda dengan tempat-tempat penyelenggaraan makanan lain, tetapi standar kebersihan dan hygiene pelayanan makanannya lebih tinggi karena rentannya pasien yang masuk rumah sakit dan ancaman penyebaran kuman pathogen yang tinggi di lingkungan rumah sakit(Widha A, 2011). Pengawasan hygiene dan sanitasi makanan di rumah sakit juga dapat didasarkan pada Kepmenkes RI Nomor 1204 tahun 2004 Tentang Persyaratan Kesehatan Lingkungan Rumah Sakit.

Rumah Sakit Umum Daerah Banyumas yang pada tahun 2001 ditetapkan menjadi Rumah Sakit Kelas B Pendidikan oleh Menteri Kesehatan. Sebagai rumah sakit kelas B, maka perlu adanya pelayanan kesehatan yang baik salah satunya instalasi gizi harus menyediakan bahan makanan yang akan diolah untuk dikonsumsi pasien setiap hari.

Penelitian sebelumnya yang dilakukan oleh Lutfi Nurlaily tahun 2014 di instalazi gizi RSUD Banyumas Kabupaten Banyumas diperoleh hasil kontaminasi Escherichia coli pada sampel oseng-oseng tidak

\footnotetext{
${ }^{*}$ E-mail: priyani.astri@gmail.com

${ }^{* *}$ E-mail: budiono.zaeni@gmail.com
}

memenuhi syarat, karena jumlah E. coli sebanyak 15,3 MPN/100 ml. Berdasarkan survei pendahuluan yang telah peneliti lakukan di Instalasi Gizi RSUD Banyumas pada tanggal 14 juli 2016 diketahui antara lain kondisi lantai ruang pengolahan yang masih kasar serta suhumencapai $32^{\circ} \mathrm{C}$ dan kelembaban mencapai $65 \%$ yang tidak memenuhi syarat, sehingga kondisi ini memungkinkan mengganggu kenyamanan bagi para penjamah. Masih dijumpai penjamah makanan yang tidak memakai sarung tangan, masker dan sebagian ada yang berbicara saat bekerja, sehingga kondisi ini memungkinkan terjadinya kontaminasi makanan dari mikroorganisme melalui penjamah makanan, alat makan yang digunakan dalam proses pemasakan dan penyajian.

Peralatan makan disimpan di dalam lemari/ rak dengan keadaan pintu terbuka, kondisi ini memungkinkan terjadinya kontaminasi makanan melalui alat makan. Berdasarkan latar belakang tersebut maka penulis tertarik untuk melakukan penelitian dengan judul “ Studi Hygiene Sanitasi Pengelolaan Makanan dan Minuman di Rumah Sakit Umum Daerah Banyumas Kabupaten Banyumas Tahun 2017”.

\section{Bahan dan Metode}

Jenis penelitian adalah deskriptif.Metode penelitian yang digunakan observasional. Metode observasional dimaksudkan melakukan pengamatan secara langsung terhadap kondisi yang ada pada instalasi gizi, khususnya pada proses pengelolaan makanan dan minuman, dan melakukan pemeriksaan laboratorium pada sampel makanan, sampel minuman, alat makan dan alat masak dan menganalisis semua data yang diolah dan dibandingkan dengan kepmenkes RI No. 1204 tahun2004 tentang Persyaratan Kesehatan Lingkungan Rumah Sakit. Pengumpulan data dilakukan dengan cara observasi, wawancara dan pemeriksaan laboratorium. Instrumen yang digunakan berupa checklist, kuesioner dan satu set unit pemeriksaan laboratorium.

\section{Hasil dan Pembahasan}

Berdasarkan hasil penelitian terhadap hygiene sanitasi pengelolaan makanan dan minuman di instalasi gizi RSUD Banyumas, dapat dilihat pada hasil dan pembahasaan sebagai berikut:

a. Hasil skor sanitasi pengelolaan makanan dan minuman di instalasi gizi RSUD Banyumas.

\begin{tabular}{|c|c|c|c|}
\hline No & Variabel & Skor & Ket \\
\hline 1 & 2 & 3 & 4 \\
\hline 1 & Pengadaan bahan makanan & $100 \%$ & MS \\
\hline & a. Sayuran & $100 \%$ & MS \\
\hline & b. Buah & $100 \%$ & MS \\
\hline & c. Biji-bijian & $100 \%$ & MS \\
\hline & d. Jenis tepung & $100 \%$ & MS \\
\hline & e. Bumbu & $100 \%$ & MS \\
\hline & f. Daging hewan ternak & $100 \%$ & MS \\
\hline
\end{tabular}




\begin{tabular}{|c|c|c|c|}
\hline No & Variabel & Skor & Ket \\
\hline \multirow[t]{3}{*}{1} & 2 & 3 & 4 \\
\hline & g. Telur & $100 \%$ & MS \\
\hline & h. Ikan & $100 \%$ & MS \\
\hline \multirow[t]{4}{*}{2} & $\begin{array}{l}\text { Penyimpanan } \\
\text { makanan }\end{array}$ & $92,85 \%$ & TMS \\
\hline & a. $\quad$ Tempat penyimpanan & $100 \%$ & MS \\
\hline & $\begin{array}{lll}\text { b. } & \begin{array}{l}\text { Penyimpanan } \\
\text { makanan kering }\end{array} & \text { bahan } \\
\end{array}$ & $100 \%$ & MS \\
\hline & $\begin{array}{ll}\text { c. } & \begin{array}{l}\text { Penyimpanan } \\
\text { makanan basah }\end{array} \\
\end{array}$ & $80 \%$ & TMS \\
\hline \multirow[t]{20}{*}{3} & Pengolahan makanan & $91,26 \%$ & TMS \\
\hline & a. $\quad$ Penjamah Makanan & $90 \%$ & TMS \\
\hline & $\begin{array}{l}\text { 1) Personal Hygiene } \\
\text { Penjamah }\end{array}$ & $100 \%$ & MS \\
\hline & 2) $\begin{array}{l}\text { Prilaku penjamah } \\
\text { makanan }\end{array}$ & $75 \%$ & TMS \\
\hline & $\begin{array}{lll}\text { b. } & \text { Cara } & \text { Pengolahan } \\
& \text { Makanan } & \\
\end{array}$ & $100 \%$ & MS \\
\hline & Alat & $88,89 \%$ & TMS \\
\hline & 1) Alat Makan & $100 \%$ & MS \\
\hline & 2) Alat Masak & $62,5 \%$ & TMS \\
\hline & Tempat & $86,27 \%$ & TMS \\
\hline & 1) Lantai & $83,33 \%$ & TMS \\
\hline & Dinding & $100 \%$ & MS \\
\hline & Langit-langit & $100 \%$ & MS \\
\hline & Ventilasi & $40 \%$ & TMS \\
\hline & Pintu & $100 \%$ & MS \\
\hline & Pencahayaan & $100 \%$ & MS \\
\hline & $\begin{array}{l}\text { 7) Ruang Pengoalahan } \\
\text { Makanan }\end{array}$ & $100 \%$ & MS \\
\hline & Tempat cuci alat & $100 \%$ & MS \\
\hline & 9) Tempat cuci tangan & $60 \%$ & TMS \\
\hline & 10) Kamar mandi & $88,89 \%$ & TMS \\
\hline & 11) Tempat sampah & $75 \%$ & TMS \\
\hline 4 & Penyimpanan makanan jadi & $100 \%$ & MS \\
\hline \multirow[t]{3}{*}{5} & Pengangkutan makanan & $80 \%$ & TMS \\
\hline & $\begin{array}{lll}\text { a. } & \begin{array}{l}\text { Cara } \\
\text { makanan }\end{array} & \text { pengangkutan } \\
\end{array}$ & $66,67 \%$ & TMS \\
\hline & $\begin{array}{lll}\text { b. } & \begin{array}{l}\text { Alat } \\
\text { makanan }\end{array} & \text { pengangkutan } \\
\end{array}$ & $100 \%$ & MS \\
\hline \multirow[t]{4}{*}{6} & Penyajian makanan & $100 \%$ & MS \\
\hline & a. Cara penyajian makanan & $100 \%$ & MS \\
\hline & $\begin{array}{lll}\text { b. } & \begin{array}{l}\text { Prilaku } \\
\text { makanan }\end{array} & \text { penyajian } \\
\end{array}$ & $100 \%$ & MS \\
\hline & $\begin{array}{ll}\text { c. } & \text { Alat penyajian makanan }\end{array}$ & $100 \%$ & MS \\
\hline \multicolumn{4}{|c|}{$\begin{array}{l}\text { engelolaan makanan dan minuman di RSUD } \\
\text { anyumas dapat dijelaskan sebagai berikut: } \\
\text { Proses pengadaan bahan makanan diperoleh hasil } \\
100 \% \text { dengan kategori memenuhi syarat. Variabel } \\
\text { penilaian didasarkan pada kwalitas dan syarat-syarat } \\
\text { layak digunakannya bahan makanan tersebut. } \\
\text { Variabel penelitian yang diamati yaitu sayuran, buah- } \\
\text { buahan, biji-bijian, jenis tepung, bumbu, daging } \\
\text { hewan ternak, telur dan ikan, semua bahan yang } \\
\text { diamati telah menunjukan adanya kesusuaian dengan } \\
\text { teori yang ada. }\end{array}$} \\
\hline
\end{tabular}

b. Proses penyimpanan bahan makanan diperoleh hasil 92,85\% dengan kategori tidak memenuhi syarat, dengan rincian variabel penilaian tempat penyimpanan diperoleh hasil $100 \%$ (memenuhi syarat), penyimpanan bahan makanan kering diperoleh hasil 100\% (memenuhi syarat), penyimpanan bahan makanan basah diperoleh hasil 80\% (tidak memenuhi syarat). Penyimpanan bahan makanan basah dikategorikan tidak memenuhi syarat karena salah satu item tidak memenuhi syarat, item penilaian tersebut mengenai penataan bahan makanan basah dalam lemari es yang terlalu padat. Perlu dilakukan penataan kembali agar sirkulasi udara antara sela bahan makananlancar dan dapat memperpanjang daya simpan bahan makanan. Hasil pengamatan terhadap proses penyimpanan bahan makanan dibandingkan dengan Kepmenkes RI No. 1204 tahun 2004 tentang Persyaratan Kesehatan Lingkungan Rumah Sakit.

c. Proses pengolahan makanan diperoleh hasil 91,26\% dengan kategori tidak memenuhi syarat, dengan rincian variabel penilaian:

1)Penjamah makanan diperoleh hasil $90 \%$ (tidak memenuhi syarat), dikategorikan tidak memenuhi syarat karena masih ditemukan penjamah yang berbicara saat mengolah makanan. Menurut Kepmenkes RI No. 715 Tahun 2003 tentang Persyaratan Hyginen Sanitasi Jasboga, penjamah makanan tidak boleh berbicara pada saat melakukan pengolahan makanan, karena pada saat mengolah makanan sambil berbicara, makanan bisa tercemar bakteri yang ada di mulut. Sebaiknya penjamah bicara seperlunya yang berkaitan dengan pekerjaan dan lebih baik lagi jika menggunakan masker. Tingkat pengetahuan penjamah tentang hygiene sanitasi makanan dan minuman diperoleh dari hasil wawancara. Peneliti mewawancarai 10 penjamah makanan menggunakan kuesioner. kuesioner yang digunakan peneliti berupa pertanyaan sederhana dengan pilihan ganda, terdapat 16 soal dengan 2 jawaban dan terdapat satu jawaban tepat diantara dua pilihan jawaban. Dari ke-10 penjamah tersebut mampu menjawab 15 pertanyaan dari 16 pertanyaan. hasil penilaian pengetahuan penjamah tentang hygiene dan sanitasi makanan memperoleh prosentase 93,75\% dengan katagori baik. Hasil wawancara sudah di kategorikan baik namun, terdapat satu pertanyaan yang dijawab tidak tepat yaitu mengenai pemeriksaan kesehatan secara berkala pada penjamah. Instalasi Gizi RSUD Banyumas belum menerapkan pemeriksaan kesehatan secara berkala minimal enam bulan sekali secara rutin, pemeriksaan kesehatan instalasi gizi RSUD Banyumas dilakukan di awal pengkrekutan tenaga penjamah makanan, dengan hal ini perlu adanya program dari instalasi gizi untuk melakukan 
pemeriksaan kesehatan penjamah makanan secara berkala minimal selama 6 bulan sekali selain itu perlu dipertahankan dan ditingkatkan adanya pelatihan tentang hygiene sanitasi pengelolaan makanan dan minuman kepada penjamah makanan agar penjamah semakin memahami tentang hygiene sanitasi makanan dan minuman.

2)Cara pengolahan makanan diperoleh hasil 75\% (tidak memenuhi syarat), dikategorikan tidak memenuhi syarat karena penjamah makanan tidak menggunakan sarung tangan pada saat mengolah makanan. Menurut Kepmenkes RI No. 715 Tahun 2003 tentang Persyaratan Hyginen Sanitasi Jasboga, dalam mengolah makanan penjamah sebaiknya menggunakan sarung tangan steril. Penggunaan sarung tangan steril bertujuan untuk menghindari kontak langsung tangan dengan makanan sehingga makanan tidak tercemar bakteri dan kotoran yang terdapat pada tangan.

3)Alat diperoleh hasil 88,89\% (tidak memenuhi syarat), dikategorikan tidak memenuhi syarat karena alat masak tidak didesinfeksi setelah dicuci. Wajan yang sudah dicuci dan tidak disimpan pada rak/tempat penyimpanan khusus sehingga dapat tercemar oleh debu dan kotoran. Menurut Kepmenkes RI No. 1204 tahun 2004 tentang Persyaratan Kesehatan Lingkungan Rumah Sakit, peralatan makan dan masak seharusnya didesinfeksi serta di simpan pada rak/lemari yang tertutup.

4)Tempat pengolahan makanan diperoleh hasil 86,27\% (tidak memenuhi syarat), dikategorikan tidak memenuhi syarat karena lantai pada instalasi gizi tidak conus sehingga sulit dibersihkan, kotoran bahkan bakteri dapat berkumpul pada sudut lantai, ventlasi tidak disertai dengan kain kasa, Penambahan kawat kasa sangat disarankan untuk menahan debu, kotoran dan serangga yang masuk melalui lubang ventilasi, tempat cuci tangan tidak dilengkapi dengan tisu steril, penggunaan tisu steril juga dapat menghindari penjamah mengeringkan tangan dengan mengusap pada baju kerja atau celemek, kamar mandi tidak terpisah antara lakilaki dan perempuan, menurut Kepmenkes 1098 tahun 2003 tentang Persyaratan Hygiene Sanitasi Rumah Makan dan Restoran, kamar mandi pria dan wanita harus terpisah, bertujuan untuk menjaga privasi pekerja. serta tempat sampah yang tidak berpenutup memudahkan untuk dijangkau oleh lalat dan binatang lain, lalat dapat masuk ke dalam ruang instalasi gizi kemudian bisa hinggap di makanan dan minuman.

d. Proses penyimpanan makanan jadi diperoleh hasil $100 \%$ dengan kategori memenuhi syarat. Hasil menunjukan adanya kesesuaian dengan Permenkes 1096 tahun 2011 tentang Hygiene Sanitasi Jasaboga. Perlu dipertahankan dan dilakukan peningkatan dalam menjaga kebersihan alat pengangkut makanan agar makanan tidak tercemar saat diangkut.

e. Proses pengangkutan makanan diperoleh hasil $80 \%$ dengan kategori tidak memenuhi syarat, dengan rincian variabel penilaian:

1)Cara pengangkutan makanan diperoleh hasil 66,67\% (tifdak memenuhi syarat), Hasil dibandingkan dengan Kepmenkes RI No. 1204 tahun 2004 tentang Persyaratan Kesehatan Lingkungan Rumah Sakit. Pengangkutan makanan menggunakan kereta dorong tertutup dengan pengisian makanan yang tidak penuh, Jalur pengangkutan makanan belum terpisah dengan jalur laundry kotor \& sampah. Pencemaran makanan dan minuman dapat terjadi jikajalur pengangkutan makanan dengan jalur pengangkutan laundry kotor dan sampah belum terpisah, sehingga perlu dilakukan pemisahan jalur pengangkutan makanan dengan jalur laundry dan sampah atau untuk diberlakukannya perbedaan jam pengangkutan dengan pengangkutan laundry kotor dan sampah.

2)Alat pengangkutan makanan diperoleh hasil 100\% (memenuhi syarat). Hasil pengamatan menunjukan adanya kesesuaian dengan Kepmenkes RI No. 1204 tahun 2004 tentang Persyaratan Kesehatan Lingkungan Rumah Sakit. Alat angkut makanan menggunakan kereta dorong yang tertutup, kereta dorong dibersihkan terlebih dahulu menggunakan kaiin lap bersih setiap akan mengangkut makanan dan terbuat dari bahan yang kuat dan aman. Perlu dipertahankan dan dilakukan peningkatan dalam menjaga kebersihan alat pengangkut makanan agar makanan tidak tercemar saat diangkut.

f. Proses penyajian makanan diperoleh hasil 100\% dengan kategori memenuhi syarat, dengan rincian variabel penilaian:

1)Cara penyajian makanan diperoleh hasil 100\% (memenuhi syarat), Hasil pengamatan menunjukan adanya kesesuaian dengan Kepmenkes RI No. 1204 tahun 2004 tentang Persyaratan Kesehatan Lingkungan Rumah Sakit, perlu dipertahankan. Penyajian makanan terhindar dari cemaran serta disajikan dalam keadaan tertutup yaitu menggunakan plastik wrap hal ini bertujuan melindungi makanan dari bahan pencemar seperti debu atau serangga atau yang lainnya. Makanan jadi segera disajikan serta tidak menyajikan makanan jadi yang sudah menginap hal ini bertujuan menjaga kualitas makanan agar tidak terkontaminasi oleh bakteri yang dapat tumbuh dalam suhu kamar.

2)Perilaku penyajian makanan diperoleh hasil 100\% (memenuhi syarat), Hasil pengamatan menunjukan adanya kesesuaian dengan Kepmenkes RI No. 1204 tahun 2004 tentang Persyaratan Kesehatan Lingkungan Rumah Sakit, perlu dipertahankan. Penyaji makanan di instalasi gizi dalam keadaan 
sehat, serta berpakaian rapi \& pelindung diri seperti celemek dan penutup rambut hal ini bertujuan untuk melindungi makanan agar tidak terkontaminasi bahan pencemar yang disebsbkan oleh pramusaji.

3)Alat penyajian makanan diperoleh hasil 100\% (memenuhi syarat). Hasil pengamatan menunjukan adanya kesesuaian dengan Kepmenkes RI No. 1204 tahun 2004 tentang Persyaratan Kesehatan Lingkungan Rumah Sakit, perlu dipertahankan. Alat penyaji sebelum digunakan sudah dicuci dan didesinfeksi menggunakan air panas sehingga alat penyaji dalam keadaan bersih. Alat penyaji dalam keadaan utuh dan tidak melepaskan zat beracun serta disimpan dalam rak khusus sehingga terlindung dari debu, serangga dan tikus. alat penyaji makanan dapat berupa alat makan seperti sendok, piring, plato, mangkuk, piring kecil dan lainnya.

b. Hasil pemeriksaan laboratorium

1) Sampel alat makan dan masak

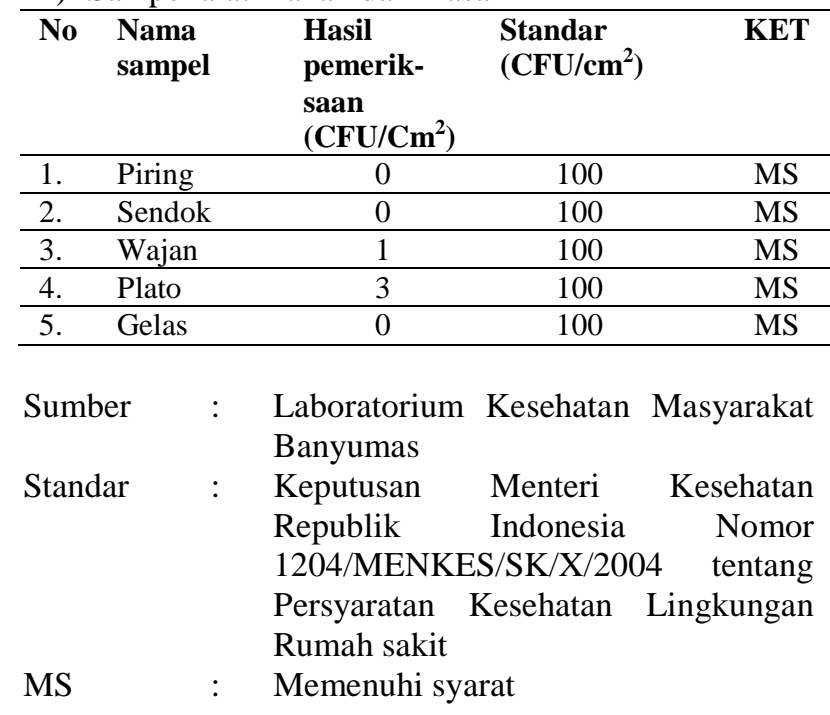

Hasil pemeriksaan Angka Lempeng Total (ALT) pada alat makan dan masak berupa sendok makan, piring, plato, gelas dan wajan, pemeriksaan ini dilakukan untuk mengetahui angka lempeng total kuman pada alat makan pasien dengan metode usap. Peneliti mengambil 1 sampel sendok dengan hasil sendok adalah $0 \mathrm{CFU} / \mathrm{cm}^{2}$, 1 sampel piring adalah $0 \mathrm{CFU} / \mathrm{cm}^{2}, 1$ sampel plato adalah $3 \mathrm{CFU} / \mathrm{cm}^{2}$, 1 sampel gelas adalah $0 \mathrm{CFU} / \mathrm{cm}^{2}$ dan 1 sampel wajan $1 \mathrm{CFU} / \mathrm{cm}^{2}$

Hasil pemeriksaan dibandingkan dengan Kepmenkes RI No. 1204/MENKES/SK.X/2004 tentang Persyaratan Kesehatan Lingkungan Rumah Sakit, angka kuman sebanyak-banyaknya 100 koloni/ $\mathrm{cm}^{2}$ permukaan, dari pemeriksaan sendok, piring, plato, gelas dan wajan seluruhnya memenuhi syarat karena tidak melebihi batas maksimal yang ditentukan.

\begin{tabular}{ccccc} 
2) Sampel makanan & & \\
\hline No & $\begin{array}{c}\text { Kode } \\
\text { sampel }\end{array}$ & $\begin{array}{c}\text { Hasil } \\
\text { Pemeriksaan } \\
\text { (MPN E. } \\
\text { Coli) }\end{array}$ & $\begin{array}{c}\text { Standar } \\
\text { (MPN } \\
\text { E. Coli) }\end{array}$ & KET \\
\hline 1 & $\begin{array}{c}\text { Semur } \\
\text { ayam 1 }\end{array}$ & 0 & $<3 / g$ & MS \\
\hline 2 & $\begin{array}{c}\text { Semur } \\
\text { ayam 2 }\end{array}$ & 0 & $<3 / g$ & MS \\
\hline 3 & $\begin{array}{c}\text { Semur } \\
\text { ayam 3 }\end{array}$ & 0 & $<3 / g$ & MS \\
\hline
\end{tabular}

$\begin{array}{lllr}\text { Sumber } & : & \text { Laboratorium Kesehatan Masyarakat } \\ \text { Standar } & \text { Banyumas } & \text { Peraturan Badan Pengawas Obat dan } \\ & & \text { Makanan No. } \\ & \text { HK.00.06.1.52.4011 tahun 2009 } \\ & \text { tentang penetapan batasmaksimal } \\ & \text { cemaran mikroba dan kimia dalam } \\ & \text { makanan. } \\ \text { MS } & \text { Memenuhi syarat }\end{array}$

Hasil pemeriksaan Esherichia coli pada sampel semur ayam yang diambil sebanyak 3 sampel hasilnya sebagai berikut: MPN E. Coli pada semur ayam 1 adalah 0, MPN E. Coli pada semur ayam 2 adalah 0 dan MPN E. Coli pada semur ayam 3 adalah 0 . Hasil pemeriksaan tersebut dibandingkan dengan Peraturan Badan Pengawas Obat dan Makanan RI No.HK.00.06.1.52.4011 tahun 2009 tentang penetapan batas maksimal cemaran mikroba dan kimia dalam makanan.Untuk semur ayam goreng batas maksimal cemaran MPN E. Coli pada adalah <3/g sampel makanan, sampel semur ayam masih memenuhi syarat karena belum melebihi batas maksimal cemarannya, perlu dipertahankan dan ditingkatkan lagi pada beberapa aspek pengelolaan makanan yang belum memenuhi syarat demi menjaga kualitas makanan.

\begin{tabular}{ccccc} 
3) Sampel minuman & & \\
\hline No & $\begin{array}{c}\text { Kode } \\
\text { sampel }\end{array}$ & $\begin{array}{c}\text { Hasil } \\
\text { Pemeriksaan } \\
\text { (MPN E. } \\
\text { Coli) }\end{array}$ & $\begin{array}{c}\text { Standar } \\
\text { (MPN E. } \\
\text { Coli) }\end{array}$ & KET \\
\hline 1 & AMK 1 & 0 & $<2 / 100 \mathrm{ml}$ & MS \\
\hline 2 & AMK 2 & 0 & $<2 / 100 \mathrm{ml}$ & MS \\
\hline 3 & AMK 3 & 0 & $<2 / 100 \mathrm{ml}$ & MS \\
\hline
\end{tabular}

Sumber : Laboratorium Kesehatan Masyarakat Standar : $\begin{aligned} & \text { Banyumas } \\ & \text { Peraturan Badan Pengawas Obat dan }\end{aligned}$ Makanan RI No. HK.00.06.1.52.4011 tahun 2009 tentang penetapan batasmaksimal cemaran mikroba dan kimia dalam makanan.

MS : Memenuhi syarat

AMK : Air Minum dalam Kemasan 
Hasil pemeriksaan Esherichia coli pada sampel air minum dalam kemasan (AMK) yang diambil sebanyak 3 sampel hasilnya adalah sebagai berikut: MPN E. Coli pada AMK 1 adalah 0 , MPN E. Coli pada AMK 2 adalah 0 dan MPN E. Coli pada AMK 3 adalah 0 . Hasil pemeriksaan tersebut dibandingkan dengan Peraturan Badan Pengawas Obat dan Makanan RI No.HK.00.06.1.52.4011 tahun 2009 tentang penetapan batas maksimal cemaran mikroba dan kimia dalam makanan.Untuk air minum dalam kemasan batas maksimal cemaran MPN E. Coli adalah $<2 / 100 \mathrm{ml}$, sampel air minum dalam kemasan masih memenuhi syarat karena belum melebihi batas maksimal cemarannya, perlu dipertahankan dan ditingkatkan lagi pada beberapa aspek pengelolaan makanan yang belum memenuhi syarat demi menjaga kualitas makanan.

\section{Kesimpulan}

a. Hasil pengamatan pengadaan bahan makanan diperoleh hasil 100\% dengan kategori memenuhi syarat.

b. Hasil pengamatan penyimpanan bahan makanan diperoleh hasil 92,85\% dengan kategori tidak memenuhi syarat..

c. Hasil pengamatan pengolahan makanan diperoleh hasil 91,26\% dengan kategori tidak memenuhi syarat.

d. Hasil pengamatan penyimpanan makanan diperoleh hasil 100\% dengan kategori memenuhi syarat.

e. Hasil pengamatan pengangkutan makanan diperoleh hasil 80\% dengan kategori tidak memenuhi syarat.

f. Hasil pengamatan penyajian makanan diperoleh hasil 100\% dengan kategori memenuhi syarat.

g. Hasil pemeriksaan Esherichia coli pada sampel semur ayam memenuhi syarat karena ketiga sampel hasil MPN E.coliadalah <3/g sampel makanan.

h. Hasil pemeriksaan Esherichia coli pada sampel air minum dalam kemasan memenuhi syarat karena ketiga sampel hasil MPN E.coliadalah $<2 / 100 \mathrm{ml}$ sampel minuman.

i. Hasil pemeriksaan Angka Lempeng Total (ALT) pada alat makan dan masak berupa sendok makan, piring, plato, gelas dan wajan memenuhi syarat karena kelima sampel hasilnya tidak melebihi batas maksimal yang ditentukan yaitu $<100 \mathrm{koloni} / \mathrm{cm}^{2}$ permukaan.

\section{Ucapan Terima Kasih}

Peneliti mengucapkan banyak terima kasih kepada pihak Rumah Sakit Umum Daerah Banyumas terutama pihak instalasi gizi RSUD Banyumas yang telah memberikan ijin penelitian di instalasi gizi RSUD Banyumas serta seluruh pihak yang telah membantu terselesaikannya penelitian ini.

\section{Daftar Pustaka:}

Depkes RI, 2004, Hygiene Sanitasi Makanan dan Minuman. Dirjen PPM dan PLP. Jakarta.

Depkes RI Dirjen PPM \& PLP. 1998. Pedoman

Pembinaan Dan Pengawasan Sanitasi Makanan

Direktorat jendral PP dan PL, 2010, Kursus Hygiene Sanitasi Makanan dan Minuman: Jakarta.

Djamaluddin Ramlan dan Maisye Marlyn Kuhu, 2013, Penulisan Penelitian Deskriptif, Purwokerto: Unsoed Press.

http://rsudbms.banyumaskab.go.id/ diakses pada tanggal 20 September 2016 pukul 22.50 WIB.

Kepmenkes RI No 1204/MENKES/SK/X/2004 Tentang Persyaratan Kesehatan Lingkungan Rumah Sakit.

No 1098/MENKES/SK/VII/2003 Tentang Persyaratan Hygiene \& Sanitasi Rumah Makan \& Restoran.

Kunto Herwibowo, N.S. Budiana, 2014, Hidroponik Sayuran, Cibubur, Jakarta Timur : Penebar Swadaya.

Nurwahyuningrum.2009 .Studi Sanitasi Alat Makan di Instalasi Gizi Rumah Sakit Umum Daerah KebumenTahun 2009. KTI, Purwokerto: Kementerian Kesehatan Semarang Jurusan Kesehatan Lingkungan Purwokerto.

Nursiah Mukrie et.all. 1996. Manajemen Sistem Penyelenggaraan Makanan Institusi (Buku Kedua). Pusdiknakes Depkes RI.

Mujianti U Cakhyanigtyas Mujianti U. 2010. Studi Tentang Hygiene Sanitasi Pengelolaan Makanan dan Minuman di Rumah Sakit Umum Daerah Prof. dr. Margono Soekarjo Purwokerto Tahun 2010. KTI, Purwokerto: Kementerian Kesehatan Semarang Jurusan Kesehatan Lingkungan Purwokerto.

Permenkes RI No 1096/MENKES/Per/VI/2011 Tentang Hygiene Sanitasi Jasa Boga.

Permenkes RI No 78 Tahun 2013 Tentang Pedoman Pelayanan Gizi Rumah Sakit.

Permenkes RI No 56 Tahun 2014 Tentang Klasifikasi dan Perizinan Rumah Sakit.

Standard Operating Procedure (SOP) Mata Kuliah Keselamatan dan Kesehatan Kerja, 2016, Pengukuran Intensitas Cahaya. Politeknik Kesehatan Kementerian Kesehatan Semarang: Jurusan Kesehatan Lingkungan Purwokerto.

Standard Operating Procedure (SOP) Mata Kuliah Penyehatan Udara, 2016, Pengukuran Suhu dan Kelembaban. Politeknik Kesehatan Kementerian Kesehatan Semarang: Jurusan Kesehatan Lingkungan Purwokerto.

Standard Operating Procedure (SOP) Mata Kuliah PMM-A, 2015, Pengambilan Sampel Makanan dan Minuman.Politeknik Kesehatan Kemenkes 
Semarang Jurusan Kesehatan Lingkungan Purwokerto.

Standard Operating Procedure (SOP) Mata Kuliah PMM-A, 2015, Deteksi Kualitas Mikrobiologi dalam Makanan dan Minuman. Politeknik Kesehatan Kementerian Kesehatan Semarang: Jurusan Kesehatan Lingkungan Purwokerto.

Standard Operating Procedure (SOP) Mata Kuliah PMM-B, 2015, Uji Sanitasi Alat Makan dan Pemeriksaan Angka Lempeng Total (ALT). Politeknik Kesehatan Kementerian Kesehatan Semarang: Jurusan Kesehatan Lingkungan Purwokerto.

Suharsimi Arikunto. 1998, Prosedur Penelitian (Edisi Revisi IV), Jakarta: PT Rineka Cipta.

Tri Cahyono, 2014, Pedoman Penulisan Proposal Penelitian Dan Karya Tulis

Ilmiah/Skripsi (Edisi Revisi Ketiga).

Kementerian Kesehatan RI Politeknik
Kesehatan Kemenkes Semarang Jurusan Kesehatan Lingkungan Purwokerto.

Undang-undang Nomor 36 Tahun 2008 Tentang Kesehatan.

Widha Aprilandini. 2011, Pengolahan Makanan, (http://widhaaprilandini. wordpress.com/ Pengolahan Makanan, diakses tanggal 12 Januari 2017). 